\title{
Clinical advantage and tolerability of ibandronate in hemodialysis patients: a retrospective study
}

\author{
Satoru Mitsuboshi ${ }^{1 *}$, Hitoshi Yamada ${ }^{1}$, Kazuhiko Nagai ${ }^{1}$ and Hideo Okajima ${ }^{2}$
}

\begin{abstract}
Background: Tartrate-resistant acid phosphatase-5b (TRACP-5b) and bone-specific alkaline phosphatase (BALP) levels have not been evaluated following ibandronate treatment in hemodialysis (HD) patients.

Methods: To evaluate the efficacy and tolerability of ibandronate, including TRACP-5b and BALP levels, in patients on $\mathrm{HD}$, we conducted a 6 -month retrospective study of $13 \mathrm{HD}$ patients who were administered ibandronate at Kaetsu Hospital in Japan. All enrolled patients were placed on a regimen of intravenous ibandronate at a dose of 1 mg once every 4 weeks, from August 2015 to October 2016. Baseline and end-of-study levels of TRACP-5b and BALP were determined 1 month before and 6 months after the start of ibandronate treatment.
\end{abstract}

Results: TRACP-5b levels were significantly decreased from $785.3 \pm 385.8 \mathrm{mU} / \mathrm{dL}$ at baseline to $638.2 \pm 423.4 \mathrm{mU} / \mathrm{dL}$ at end of study $(P=0.03)$. Additionally, the changing levels of TRACP-5b were positively associated with baseline hip bone mineral density (BMD) $(P=0.02, r=0.65)$. In contrast, BALP levels were not significantly changed. Moreover, hip BMD tended to decrease from $0.51 \pm 0.10 \mathrm{~g} / \mathrm{cm}^{2}$ at baseline to $0.47 \pm 0.11 \mathrm{~g} / \mathrm{cm}^{2}$ at end of study $(P=0.07)$. The tolerability index showed no statistical difference between baseline and end of study.

Conclusion: Our results indicate that ibandronate treatment in HD patients_especially those with low BMD - might sufficiently reduce TRACP-5b levels with no long-term changes in other clinical laboratory parameters. Therefore, ibandronate might be a feasible treatment option for HD patients who develop low BMD.

Keywords: Ibandronate, Tartrate-resistant acid phosphatase-5b, Bone-specific alkaline phosphatase, Bone mineral density, Hemodialysis

\section{Background}

Hemodialysis (HD) patients have a fourfold higher incidence of hip fracture compared with the general population [1]. Also, hip fractures are associated with low bone mineral density (BMD) [2] and increasing risk of mortality [3]. Thus, proper treatment is important in HD patients with low BMD.

Bisphosphonates are valuable agents for the treatment of low BMD [4] and provide vertebral and non-vertebral antifracture efficacy [5]. Ibandronate is a bisphosphonate that is available for intravenous use. A study in HD patients showed that about $36 \%$ of intravenously administered

\footnotetext{
* Correspondence: ccrtyo34057@gmail.com

'Department of Pharmacy, Kaetsu Hospital, 1459-1 Higashikanazawa,

Akiha-ku, Niigata-shi, Niigata 956-0814, Japan

Full list of author information is available at the end of the article
}

ibandronate $1 \mathrm{mg}$ was removed from the plasma after one HD session, and plasma ibandronate concentrations were close to the lower quantification limit after three HD sessions [6]. Thus, in HD patients, a suggested monthly dose of $1 \mathrm{mg}$ ibandronate should not result in plasma accumulation of ibandronate. Additionally, in HD patients, ibandronate $2 \mathrm{mg}$ every 4 weeks was shown to significantly increase BMD and decrease bone turnover after 48 weeks [7]. However, little information is available regarding the efficacy and safety of ibandronate in HD patients.

In HD patients, bisphosphonate treatment is evaluated using the following markers of bone metabolism: tartrateresistant acid phosphatase-5b (TRACP-5b) as a bone resorption marker and bone-specific alkaline phosphatase (BALP) as a bone formation marker because these markers showed no influence on renal dysfunction during an HD session [8]. 
Table 1 Patient profiles

\begin{tabular}{ll}
\hline Patient characteristics & $N=13$ \\
\hline Mean age, years \pm SD & $78 \pm 10$ \\
Sex, female/male & $4 / 9$ \\
Mean dry weight, $\mathrm{kg} \pm \mathrm{SD}$ & $47 \pm 7$ \\
Mean years of hemodialysis \pm SD & $13 \pm 9$ \\
Etiology of renal disease, $n$ & \\
$\quad$ Glomerulonephritis & 6 \\
Nephrosclerosis & 3 \\
Diabetic kidney disease & 2 \\
Other & 2 \\
Mean hip BMD, g/cm \pm SD & $0.52 \pm 0.12$
\end{tabular}

$S D$ standard deviation, $B M D$ bone mineral density

However, although TRACP-5b markers are useful for monitoring bisphosphonate treatment $[9,10]$, no data have been examined for TRACP-5b and BALP levels following ibandronate treatment in HD patients. Therefore, this study aimed to evaluate the efficacy and tolerability of ibandronate in HD patients, including the TRACP-5b and BALP levels.

\section{Methods}

This 6-month retrospective study involved HD patients who had been receiving ibandronate at Kaetsu Hospital. All enrolled patients whose BMD was less than $80 \%$ of the mean BMD for young adults were started on intravenous ibandronate at a dose of $1 \mathrm{mg}$ once every 4 weeks from August 2015 to October 2016. Baseline and the end of the study were defined as 1 month before and 6 months after the start of ibandronate treatment, respectively.

Hip BMD, TRACP-5b, and BALP representing the efficacy indexes were assessed at baseline and end of study. Additionally, to evaluate factors influencing changing levels of TRACP-5b, we examined the relationship between changes in the levels of TRACP-5b and the patients' backgrounds.

Table 2 Drug treatments administered to patients at baseline and at the end of the study period

\begin{tabular}{lll}
\hline & Baseline & End of study \\
\hline Anti-hypertensive agents & & \\
Angiotensin receptor blocker & 5 & 5 \\
Calcium channel blocker & 6 & 6 \\
Alpha adrenergic blocker & 2 & 2 \\
Beta blockers & 2 & 2 \\
HMG-CoA reductase inhibitors & 0 & 0 \\
Cinacalcet, $n$ & 2 & 2 \\
Oral vitamin D & 3 & 3 \\
Intravenous vitamin D & 8 & 8 \\
Calcium polystyrene sulfonate & 1 & 1 \\
\hline
\end{tabular}

Values represent number of medicines, $n$ HMG-COA hydroxymethylglutaryl-coenzyme A
Moreover, the levels of the following clinical parameters were considered as an overall tolerability index and were measured at baseline and end of study: hemoglobin, hematocrit, platelet count, blood urea nitrogen, serum creatinine, serum sodium, serum potassium, serum chloride, serum calcium, serum inorganic phosphorus, aspartate transaminase (AST), alanine aminotransferase (ALT), alkaline phosphatase, lactate dehydrogenase, total protein, and intact parathyroid hormone (iPTH). Serum calcium was adjusted when the serum albumin level was less than $4.0 \mathrm{~g} / \mathrm{dL}$ (adjusted serum calcium = serum calcium - serum albumin $+4.0 \mathrm{~g} / \mathrm{dL}$ ) [11]. Hepatotoxicity was defined as a threefold increase in AST or ALT levels from the upper limit of baseline [12]. Also, blood samples were obtained via vascular access before HD sessions.

Continuous values were expressed as means \pm standard deviation. Statistical analysis was performed using paired $t$ test, Mann-Whitney $U$ test, and Pearson's correlation coefficient test. Significance was set at $P<0.05$. The software package JMP 9 (SAS Institute Inc., Cary, $\mathrm{NC}$ ) was used for all statistical analysis.

\section{Results}

Fourteen HD patients were started on ibandronate treatment between August 2015 and October 2016. However, data from only 13 patients were included in this study because 1 patient was excluded following hospitalization for severe infectious disease during the observation period. Thirteen HD patients continued ibandronate treatment during the observation period. All 13 patients had oliguria or anuria and did not undergo bone biopsy. One patient had been receiving monthly intraarticular injections of $8 \mathrm{mg}$ dexamethasone for 3 years before the study period.

Patient profiles are shown in Table 1, and drug treatments are listed in Table 2. During the study period, HD background, cinacalcet, oral and intravenous vitamin D, and administration of calcium polystyrene sulfonate remained unchanged. In phosphate binders, 2 patients added lanthanum carbonate and 1 patient added ferric citrate hydrate. Hematinics (iron and other erythropoiesisstimulating agents) were adjusted according to patient status during the study period.

Changes in markers of bone metabolism and hip BMD during the observation period are shown in Table 3 .

Table 3 Changes in markers of bone metabolism and hip BMD during the observation period

\begin{tabular}{llll}
\hline & Baseline & End of study & $P^{*}$ \\
\hline TRACP-5b $(\mathrm{mU} / \mathrm{dL})$ & $785.3 \pm 385.8$ & $638.2 \pm 423.4$ & 0.03 \\
BALP $(\mu \mathrm{g} / \mathrm{L})$ & $18.1 \pm 11.4$ & $17.4 \pm 10.3$ & 0.55 \\
Hip BMD $\left(\mathrm{g} / \mathrm{cm}^{2}\right), n=9$ & $0.51 \pm 0.10$ & $0.47 \pm 0.11$ & 0.07 \\
\hline
\end{tabular}

Values represent mean \pm standard deviation

TRACP- $5 b$ tartrate-resistant acid phosphatase- $5 \mathrm{~b}, B A L P$ bone-specific alkaline phosphatase, $B M D$ bone mineral density

*Paired $t$ test $(P<0.05)$ 
TRACP-5b levels significantly decreased from $785.3 \pm$ $385.8 \mathrm{mU} / \mathrm{dL}$ at baseline to $638.2 \pm 423.4 \mathrm{mU} / \mathrm{dL}$ at end of study $(P=0.03)$. Levels of TRACP-5b decreased in 11 patients and increased in 2 patients (Table 4). Additionally, we examined the relationship between changing levels of TRACP-5b and the patients' backgrounds. As a result, the changing levels of TRACP-5b were positively associated with the baseline hip BMD $(P=0.02, r=0.65$; Fig. 1). Levels of TRACP-5b were significantly decreased in female patients compared with male patients $(-359.8$ \pm 94.9 vs $-52.7 \pm 172.2, P<0.01$, Mann-Whitney $U$ test). In contrast, BALP levels were not significantly changed from $18.1 \pm 11.4 \mu \mathrm{g} / \mathrm{L}$ at baseline to $17.4 \pm 10.3 \mu \mathrm{g} / \mathrm{L}$ at end of study $(P=0.55)$. Moreover, hip BMD tended to decrease from $0.51 \pm 0.10 \mathrm{~g} / \mathrm{cm}^{2}$ at baseline to $0.47 \pm$ $0.11 \mathrm{~g} / \mathrm{cm}^{2}$ at end of study $(P=0.07)$. However, hip BMD could not be assessed in 4 patients. One patient died as a result of an accident outside of the hospital, and 3 patients had not yet undergone hip BMD measurement during the observation period.

Changes in clinical laboratory data (representing the tolerability index) during the observation period are shown in Table 5. AST and ALT were significantly decreased from $11.8 \pm 4.1 \mathrm{U} / \mathrm{L}$ and $8.6 \pm 2.8 \mathrm{U} / \mathrm{L}$ at baseline to $9.4 \pm 3.0 \mathrm{U} / \mathrm{L}$ and $6.7 \pm 2.6 \mathrm{U} / \mathrm{L}$ at end of study, respectively $(P=0.03$ and $P<0.01)$. The other tolerability index showed no statistical difference at baseline compared with 6 months after the start of ibandronate treatment. Serum calcium levels $<8.4 \mathrm{mEq} / \mathrm{L}$ were seen in 2 patients at baseline and in 5 patients at end of study. In contrast, in 1 patient, AST and ALT levels were increased threefold from the upper limit of baseline at 3 months after start of ibandronate treatment. However, although the patient continued ibandronate treatment,
AST and ALT levels were decreased to baseline. Additionally, none of the other patients had laboratory values indicating hepatotoxicity during the observation period. Also, none withdrew from the study due to adverse effects or allergic reactions.

\section{Discussion}

TRACP-5b levels were significantly decreased after administration of ibandronate, and the baseline hip BMD and changing levels of TRACP-5b showed a statistically significant correlation. Thus, we have shown that ibandronate treatment decreases TRACP-5b levels in HD patients, and that HD patients who had lower hip BMD might demonstrate improved TRACP-5b levels. Also, levels of TRACP-5b were significantly decreased in female patients compared with male patients because female patients had lower BMD compared with male patients (Fig. 1). Both sexes lose BMD at relatively slow rates starting at around age 40, with women showing a more rapid BMD decline than men with the onset of menopause in their late 40s or early 50s [13]. Thus, female patients might demonstrate improved TRACP-5b levels. The mechanism underlying the association between the baseline hip BMD and changing levels of TRACP-5b is unclear. However, elevated bone turnover was associated with low BMD [14] and was associated with efficacy of bisphosphonate treatment [15]. Therefore, these results suggest that patients with lower hip BMD might respond more effectively to ibandronate treatment. Additionally, although 2 patients did not take vitamin D3 and 1 patient received steroids during the study period, all 3 of these patients had decreased TRACP-5b levels. Therefore, these patients might be expected to have a demonstrable effect of ibandronate treatment.

Table 4 Changes in TRACP-5b levels during the study period

\begin{tabular}{|c|c|c|c|c|c|c|c|c|}
\hline Patient & Sex & Age (years) & $\begin{array}{l}\text { Baseline iPTH } \\
\text { (pg/mL) }\end{array}$ & $\begin{array}{l}\text { Baseline serum } \\
\text { calcium (mEq/L) }\end{array}$ & $\begin{array}{l}\text { Baseline BALP } \\
(\mu \mathrm{g} / \mathrm{L})\end{array}$ & $\begin{array}{l}\text { Baseline TRACP-5b } \\
(\mathrm{mU} / \mathrm{dL})\end{array}$ & $\begin{array}{l}\text { End of study TRACP-5b } \\
\text { (mU/dL) }\end{array}$ & $\begin{array}{l}\text { Changing levels of } \\
\text { TRACP-5b (mU/dL) }\end{array}$ \\
\hline 1 & Female & 80 & 69 & 8.5 & 12.6 & 1110 & 656 & -454 \\
\hline 2 & Male & 68 & 279 & 9.4 & 15.5 & 656 & 754 & +98 \\
\hline 3 & Male & 89 & 478 & 9.2 & 9.6 & 346 & 256 & -90 \\
\hline 4 & Male & 57 & 246 & 8.8 & 12.1 & 641 & 584 & -57 \\
\hline 5 & Male & 67 & 238 & 8.8 & 17.6 & 1070 & 946 & -124 \\
\hline 6 & Female & 71 & 474 & 8.4 & 19.3 & 633 & 366 & -267 \\
\hline 7 & Male & 92 & 280 & 8.2 & 11.5 & 933 & 684 & -249 \\
\hline 8 & Male & 83 & 50 & 9.3 & 6.5 & 425 & 195 & -230 \\
\hline 9 & Male & 78 & 42 & 8.6 & 9.7 & 301 & 179 & -122 \\
\hline 10 & Female & 85 & 773 & 10.1 & 36.8 & 1400 & 1110 & -290 \\
\hline 11 & Female & 88 & 167 & 8.4 & 31.9 & 986 & 558 & -428 \\
\hline 12 & Male & 78 & 65 & 8.7 & 10.1 & 338 & 328 & -10 \\
\hline 13 & Male & 79 & 542 & 8.1 & 41.6 & 1370 & 1680 & +310 \\
\hline
\end{tabular}

iPTH intact parathyroid hormone, TRACP-5b tartrate-resistant acid phosphatase- $5 \mathrm{~b}$, BALP bone-specific alkaline phosphatase 


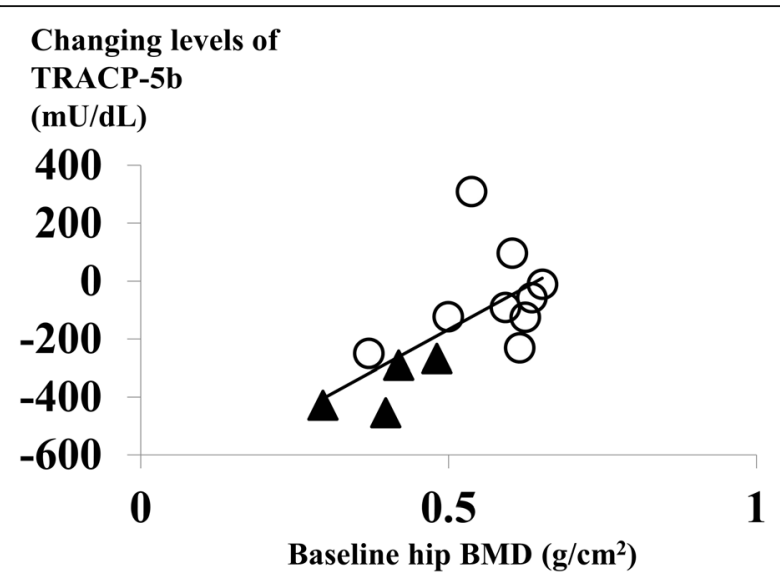

Fig. 1 Relationship between baseline hip BMD and changing levels of TRACP-5b. Pearson's correlation coefficient test. A statistically significant correlation was observed $(r=0.65 ; P=0.02)$. TRACP-5b, tartrate-resistant acid phosphatase-5b; BMD, bone mineral density. White circle: male; black triangle: female

In this study, BALP levels were not significantly changed, and hip BMD tended to decrease. However, no data are available regarding the BALP levels in HD patients on ibandronate treatment. Conversely, Bergner et al. reported that 48 weeks of ibandronate treatment significantly increased lumbar spine BMD in HD patients [7]. Additionally, in non-HD patients,

Table 5 Changes in clinical laboratory data during the observation period

\begin{tabular}{llll}
\hline & Baseline & End of study & $P^{*}$ \\
\hline Hemoglobin $(\mathrm{g} / \mathrm{dL})$ & $10.2 \pm 1.3$ & $10.1 \pm 0.8$ & 0.75 \\
Hematocrit $(\%)$ & $31.7 \pm 3.9$ & $31.2 \pm 2.5$ & 0.66 \\
Platelet count $\left(\times 10^{4} \mathrm{cells} / \mathrm{mm}^{3}\right)$ & $16.2 \pm 5.7$ & $16.1 \pm 5.3$ & 0.86 \\
Blood urea nitrogen $(\mathrm{mg} / \mathrm{dL})$ & $57.0 \pm 13.3$ & $60.7 \pm 11.8$ & 0.31 \\
Serum creatinine $(\mathrm{mg} / \mathrm{dL})$ & $9.6 \pm 2.2$ & $10.0 \pm 2.5$ & 0.55 \\
Serum sodium $(\mathrm{mEq} / \mathrm{L})$ & $137.7 \pm 2.2$ & $137.0 \pm 2.4$ & 0.09 \\
Serum potassium $(\mathrm{mEq} / \mathrm{L})$ & $4.8 \pm 0.6$ & $5.2 \pm 0.9$ & 0.08 \\
Serum chloride $(\mathrm{mEq} / \mathrm{L})$ & $107.1 \pm 2.4$ & $107.0 \pm 2.0$ & 0.93 \\
Serum calcium $(\mathrm{mEq} / \mathrm{L})$ & $8.8 \pm 0.6$ & $8.8 \pm 0.7$ & 0.84 \\
Serum inorganic phosphorus & $5.2 \pm 1.1$ & $5.2 \pm 1.5$ & 0.99 \\
(mEq/L) & & & 0.0 \\
Aspartate transaminase $(\mathrm{U} / \mathrm{L})$ & $11.8 \pm 4.1$ & $9.4 \pm 3.0$ & 0.03 \\
Alanine aminotransferase $(\mathrm{U} / \mathrm{L})$ & $8.6 \pm 2.8$ & $6.7 \pm 2.6$ & $<0.01$ \\
Alkaline phosphatase $(\mathrm{U} / \mathrm{L})$ & $278.8 \pm 102.1$ & $265.2 \pm 111.6$ & 0.34 \\
Lactate dehydrogenase $(\mathrm{U} / \mathrm{L})$ & $176.1 \pm 24.1$ & $170.6 \pm 35.4$ & 0.41 \\
Total protein $(\mathrm{g} / \mathrm{dL})$ & $6.2 \pm 0.5$ & $6.2 \pm 0.6$ & 0.95 \\
Intact PTH (pg/mL) & $284.8 \pm 224.4$ & $306.1 \pm 355.1$ & 0.71 \\
\hline Values represent mean & & &
\end{tabular}

Values represent mean \pm standard deviation

PTH parathyroid hormone

*Paired $t$ test $(P<0.05)$ percent decreases in median BALP levels from baseline were significantly greater with ibandronate versus placebo for 1 year [16]. Moreover, a meta-analysis demonstrated that 2 years of ibandronate treatment improved hip BMD [17]. Further, short-term BMD monitoring (less than 5 years) cannot achieve a high degree of explained variation in BMD change at current levels of DXA performance [18]. Therefore, BALP levels might be decreased and hip BMD might be increased when the treatment period is extended for more than 1 year.

In 1 patient, AST and ALT levels were increased threefold from the upper limit of baseline at 3 months after the start of ibandronate treatment. However, the possibility of hepatotoxicity as an adverse event was considered low. Because of this, the patient continued ibandronate treatment, so AST and ALT levels eventually decreased to baseline. Also, none of the other patients had laboratory findings suggestive of hepatotoxicity during the observation period; AST and ALT were significantly decreased after the observation period. On the other hand, serum calcium levels were not significantly changed, and patients with serum calcium levels $<8.4 \mathrm{mEq} / \mathrm{L}$ tended to show increased levels after the observation period. However, other clinical laboratory data such as the tolerability index showed no significant changes from the baseline to end of study. These results suggest that 6 months of ibandronate treatment was well tolerated in the HD patients in our study because no patients experienced hepatotoxicity, allergic reactions, or other adverse effects. Nevertheless, it may be important to monitor serum calcium in HD patients receiving ibandronate therapy.

Liu et al. reported that bisphosphonates should be carefully considered with specific requirements in HD patients because the use of bisphosphonates may aggravate clinical symptoms in patients with low bone turnover (BALP $<20 \mathrm{ng} / \mathrm{mL}$ and iPTH $<100 \mathrm{pg} / \mathrm{mL}$ ) $[19,20]$. However, our study did not examine bone biopsy. Additionally, although this study included 4 patients with low bone turnover (BALP $<20 \mathrm{ng} / \mathrm{mL}$ and $\mathrm{iPTH}<100 \mathrm{pg} / \mathrm{mL}$ ), all 4 patients demonstrated decreased TRACP-5b levels (maximum value and minimum values changed by -454 and -10 , respectively). Therefore, in these patients, bisphosphonate efficacy should be carefully monitored.

Our study has some limitations. These include the small sample size, lack of a control group, and no bone biopsy. Additionally, the study period was too short to evaluate changes in BMD and patients who had a tendency toward high iPTH were included. Therefore, more robust long-term studies are needed to confirm these findings. 


\section{Conclusions}

Taken together, our results indicate that ibandronate treatment in HD patients-especially those with low BMD - might sufficiently reduce TRACP-5b levels, with no long-term changes in other clinical laboratory parameters. Therefore, ibandronate might be a feasible treatment option for HD patients who develop low BMD.

\section{Abbreviations}

ALT: Alanine aminotransferase; AST: Aspartate transaminase; BALP: Bonespecific alkaline phosphatase; BMD: Bone mineral density; HD: Hemodialysis; IPTH: Intact parathyroid hormone; TRACP-5b: Tartrate-resistant acid phosphatase- $5 b$

\section{Acknowledgements}

The authors thank the hospital staff and patients who participated in this study.

\section{Funding}

The authors have received no research funds.

\section{Availability of data and materials}

The dataset supporting the conclusions of this article is included within the article.

\section{Authors' contributions}

SM and $\mathrm{HO}$ designed the study. SM performed the statistical analysis and wrote the manuscript. HY and KN performed the data analysis and critical review of manuscript. All authors participated in the care of the patients. All authors read and approved the final manuscript.

\section{Ethics approval and consent to participate}

This study was performed in accordance with the principles found in the Declaration of Helsinki and was approved by the Ethics Committee of Kaetsu Hospital (Permit Number: H29-004).

\section{Consent for publication}

Not applicable

\section{Competing interests}

The authors declare that they have no competing interests.

\section{Publisher's Note}

Springer Nature remains neutral with regard to jurisdictional claims in published maps and institutional affiliations.

\section{Author details}

${ }^{1}$ Department of Pharmacy, Kaetsu Hospital, 1459-1 Higashikanazawa, Akiha-ku, Niigata-shi, Niigata 956-0814, Japan. ${ }^{2}$ Department of Internal Medicine, Kaetsu Hospital, 1459-1 Higashikanazawa, Akiha-ku, Niigata-shi, Niigata 956-0814, Japan.

\section{Received: 29 August 2017 Accepted: 4 January 2018}

\section{Published online: 24 January 2018}

\section{References}

1. Alem AM, Sherrard DJ, Gillen DL, Weiss NS, Beresford SA, Heckbert SR, Wong C, Stehman-Breen C. Increased risk of hip fracture among patients with end-stage renal disease. Kidney Int. 2000;58(1):396-9.

2. Atsumi K, Kushida K, Yamazaki K, Shimizu S, Ohmura A, Inoue T. Risk factors for vertebral fractures in renal osteodystrophy. Am J Kidney Dis. 1999:33(2):287-93.

3. Fisher ES, Baron JA, Malenka DJ, Barrett JA, Kniffin WD, Whaley FS, Bubolz TA. Hip fracture incidence and mortality in New England. Epidemiology. 1991;2(2):116-22.

4. Perazella MA, Markowitz GS. Bisphosphonate nephrotoxicity. Kidney Int. 2008;74(11):1385-93.

5. Boonen S, Laan RF, Barton IP, Watts NB. Effect of osteoporosis treatments on risk of non-vertebral fractures: review and meta-analysis of intention-totreat studies. Osteoporos Int. 2005;16(10):1291-8.
6. Bergner R, Dill K, Boerner D, Uppenkamp M. Elimination of intravenously administered ibandronate in patients on haemodialysis: a monocentre open study. Nephrol Dial Transplant. 2002;17(7):1281-5.

7. Bergner R, Henrich D, Hoffmann M, Schmidt-Gayk H, Lenz T, Upperkamp M. Treatment of reduced bone density with ibandronate in dialysis patients. J Nephrol. 2008;21(4):510-6.

8. Yamada S, Inaba M, Kurajoh M, Shidara K, Imanishi Y, Ishimura E, Nishizawa Y. Utility of serum tartrate-resistant acid phosphatase (TRACP5b) as a bone resorption marker in patients with chronic kidney disease: independence from renal dysfunction. Clin Endocrinol. 2008;69(2):189-96.

9. Nenonen A, Cheng S, Ivaska KK, Alatalo SL, Lehtimäki T, Schmidt-Gayk H, Uusi-Rasi K, Heinonen A, Kannus P, Sievänen H, Vuori I, Väänänen HK, Halleen JM. Serum TRACP 5b is a useful marker for monitoring alendronate treatment: comparison with other markers of bone turnover. J Bone Miner Res. 2005:20(10):1804-12.

10. Mehlhorn AT, Rechl H, Gradinger R, Stemberger A. Alendronate decreases TRACP 5b activity in osteoarthritic bone. Eur J Med Res. 2008;13(1):21-5.

11. Payne RB, Little AJ, Williams RB, Milner JR. Interpretation of serum calcium in patients with abnormal serum proteins. Br Med J. 1973;4(5893):643-6.

12. Seki M, Yabuno K, Miyawaki K, Miwa Y, Tomono K. Loading regimen required to rapidly achieve therapeutic trough plasma concentration of teicoplanin and evaluation of clinical features. Clin Pharmacol. 2012:4:71-5.

13. Clarke BL, Khosla S. Physiology of bone loss. Radiol Clin N Am. 2010; 48(3):483-95.

14. Melton $L J$ 3rd, Khosla S, Atkinson EJ, O'Fallon WM, Riggs BL. Relationship of bone turnover to bone density and fractures. J Bone Miner Res. 1997;12(7):1083-91.

15. Bauer DC, Garnero P, Hochberg MC, Santora A, Delmas P, Ewing SK, Black DM, Fracture Intervention Research Group. Pretreatment levels of bone turnover and the antifracture efficacy of alendronate: the fracture intervention trial. J Bone Miner Res. 2006:21(2):292-9.

16. Orwoll ES, Binkley NC, Lewiecki EM, Gruntmanis U, Fries MA, Dasic G. Efficacy and safety of monthly ibandronate in men with low bone density. Bone. 2010;46(4):970-6.

17. Hou Y, Gu K, Xu C, Ding H, Liu C, Tuoheti Y. Dose-effectiveness relationships determining the efficacy of ibandronate for management of osteoporosis: a meta-analysis. Medicine (Baltimore). 2015:94(26):e1007.

18. Leslie WD, Majumdar SR, Morin SN, Lix LM. Why does rate of bone density loss not predict fracture risk? J Clin Endocrinol Metab. 2015;100(2):679-83.

19. Liu WC, Yen JF, Lang CL, Yan MT, Lu KC. Bisphophonates in CKD patients with low bone mineral density. ScientificWorldJournal. 2013;2013:837573.

20. Ureña P, Hruby M, Ferreira A, Ang KS, de Vernejoul MC. Plasma total versus bone alkaline phosphatase as markers of bone turnover in hemodialysis patients. J Am Soc Nephrol. 1996;7(3):506-12.

Submit your next manuscript to BioMed Central and we will help you at every step:

- We accept pre-submission inquiries

- Our selector tool helps you to find the most relevant journal

- We provide round the clock customer support

- Convenient online submission

- Thorough peer review

- Inclusion in PubMed and all major indexing services

- Maximum visibility for your research

Submit your manuscript at www.biomedcentral.com/submit
Biomed Central 